\title{
Climate Intelligence, a Strategy for Sustainable Urban Tourism Development in Historic City of Gaz Borkhar, Isfahan, Iran
}

\author{
Elham Zadbagher-Seghalani ${ }^{1}$, Saeid yaghoubzadeh ${ }^{2}$, Kaveh Ostad-Ali-Askari ${ }^{3 *}$, Saeid \\ Eslamian $^{4}$, Vijay P. Singh ${ }^{5}$, Nicolas R. Dalezios ${ }^{6}$ \\ ${ }^{I}$ Municipality of Gaz Borkhar, Isfahan Province, Isfahan, Iran. \\ ${ }^{2}$ Office of Natural Resources of Gaz Borkhar, Isfahan Province, Isfahan, Iran. \\ ${ }^{3 *}$ Department of Civil Engineering, Isfahan (Khorasgan) Branch, Islamic Azad University, Isfahan, Iran. \\ ${ }^{4}$ Department of Water Engineering, Isfahan University of Technology, Isfahan, Iran. \\ ${ }^{5}$ Department of Biological and Agricultural Engineering \& Zachry Department of Civil Engineering, Texas A \\ and M University, 321 Scoates Hall, 2117 TAMU, College Station, Texas 77843-2117, U.S.A. \\ ${ }^{6}$ Laboratory of Hydrology, Department of Civil Engineering, University of Thessaly, Volos, Greece \& \\ Department of Natural Resources Development and Agricultural Engineering, Agricultural University of \\ Athens, Athens, Greece.
} *Corresponding Author: Dr. Kaveh Ostad-Ali-Askari, Department of Civil Engineering, Isfahan (Khorasgan)
Branch, Islamic Azad University, Isfahan, Iran.

\begin{abstract}
Climate intelligence denotes compatibility ability of a land's people in contrast to the good and bad climate of that region. Climate intelligence in old and historic cities of the country leads to culture, buildings, and structures, which are famous as tangible and intangible heritage. Around the old Caravansary of Gaz town, where surrounding the Caravansary that has been survived from aggression and land usage change by the owners, there are the gardens built in 5-6-meter depth of the ground surface. These gardens have been established in this way for coordination with climatic conditions such as wind, humidity, and access to water source (the adjacent aqueduct). Now that necessity for understanding the climate and confrontation with its changes has been raised after the years, these pistachio gardens are suitable examples of climatic sustainability, which are able to guide the farmers and gardeners in similar climatic regions. In addition, they can be also used as urban green space in touristic region and public rest place. Thus, in addition to using a pleasant space, the visitors also are familiarized with unknown parts of thinking of the pasts, and can observe part of Iranian cultivation and culture in coordination with the climate.
\end{abstract}

Keywords: Climate intelligence, sustainable tourism, pistachio garden, aqueduct, Gaz Borkhar

\section{INTRODUCTION}

Diverse climate and sometimes, violent nature has caused that residents of these regions attempt to have inventions and innovations in coping with natural conditions. Developing abilities of people over the time for compatibility with their living region's climate constitutes climate intelligence. In this study, historical city of Gaz Borkhar and the trees planted in the deep gardens besides a beautiful historical building and its potential in creating a recreational space for tourists is investigated. These gardens can be studied in terms of tourism in two ways. One is planting trees in this form, which is a smart technique agriculturally in using water resources and controlling destruction resulting from temporal winds. On the other hand, presence of various aqueducts suggests water deficiency and attempt of people in achievement to water. Therefore, those visiting Gaz town, in addition to observe historical buildings including caravansary, can relax and enjoy in these regenerated gardens, and get familiar with the value of water and soil for the people of the region.

The historic town of Gaz Borphar is located in a relatively flat plain with a total area of $27 \mathrm{~km}^{2}$, which has no natural terrain. The city is located $8 \mathrm{~km}$ north of Isfahan and is adjacent to the Isfahan-Tehran highway. In terms of administrative division, it is a town of Isfahan province, Shahinshahr and Meymeh town (Figure 1). 
Gaz Caravansary is located near Isfahan - Tehran Highway and can accommodate domestic and foreign tourists (Picture 2) [1-26].

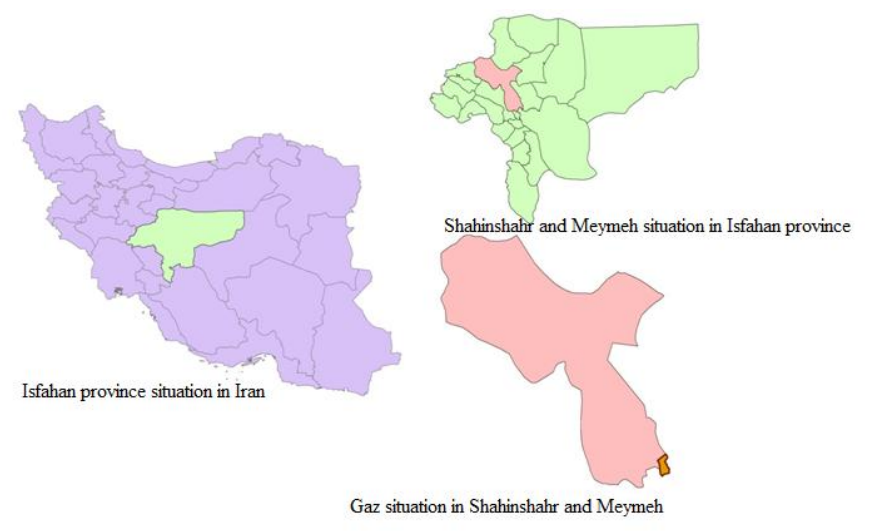

Figure1. Situation of Gaz town in Isfahan province and Shahinshahr and Meymeh town

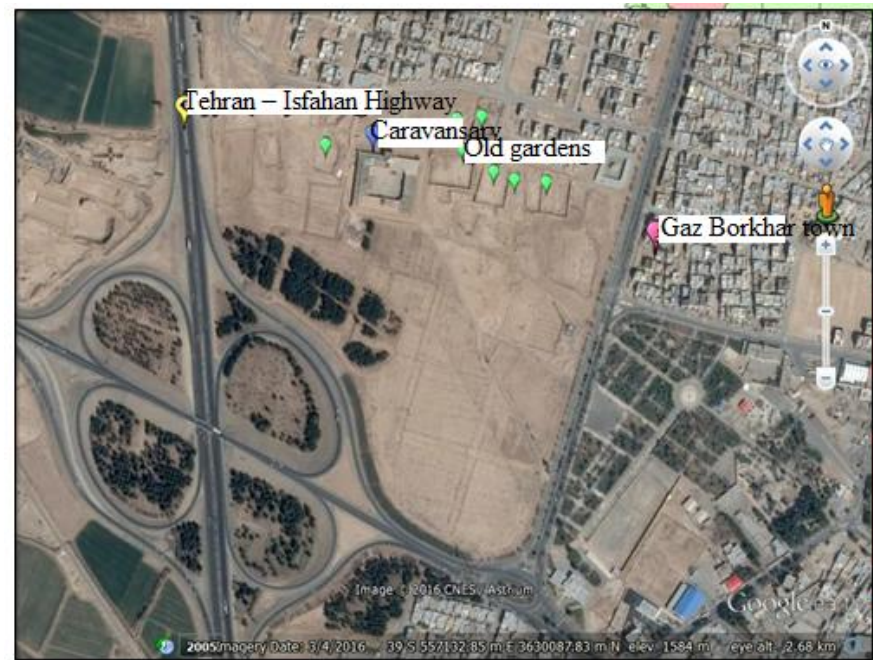

Figure2. Situation of caravansary and old pistachio gardens in vicinity to Gaz town and Isfahan - Tehran Highway

Gaz has semi-arid climate in terms of climate and it is considered as mild semi-desert climate climatologically. Its rainfall is lower than Isfahan and its evaporation is higher than Isfahan. The soils of the region are generally clay with relatively high adhesion with a little amount of sand. Although now Gaz is famous for car exhibitions and brick production, it dates back to the advent of Islam. Although now Gaz is famous for car exhibitions and brick production, it dates back to the advent of Islam. Hamdullah Mostofi in "Nazhat-ol-Gholub" wrote: "Bahman Ibn Isfandiyar built a fire temple in village Jaz (Arabic pronunciation of Gaz). Seemingly this fire temple was turned into the mosque following invasion of Arabs to Iran and influence of the Islam."

Gaz Borphar, with ancient Namaz Hill remaining from the Parthian era, is the oldest archaeological document of the region and it has the grave of Khamra. Gaz Jame Mosque, Abbasi Caravansary, Museum of Anthropology of Borkhar, Agha Mahmoud Mosque, Imamzadeh Shah Nematollah Holy Shrine, Sadat Cemetery, Adib Boroumand Cultural Foundation, old bulwark of city, Aminyan and Suleiman old houses, and Bagh Salar are among the historic monuments of Gaz town which can familiarize tourists with natural culture of this city [27-49].

Agriculture of Gaz was famous in the past. Existence of numerous aqueducts in the region indicates a long and lively history of the population in agriculture. However, successive droughts and the deep excavation in the region, and lack of due maintenance and dredging have caused dehydration of the town's aqueducts, descended groundwater, and thus, agricultural stagnation and the destruction of gardens. In the past, pistachio trees in Isfahan were planted only in Jarghuye and Gaz Borphar regions. Presence of pistachio gardens in Gaz Borkhar made wealth for the owners. Some of these 
Climate Intelligence, a Strategy for Sustainable Urban Tourism Development in Historic City of Gaz Borkhar, Isfahan, Iran

gardens had beautiful stone doors. Name of the owner and the garden construction date were engraved on the doors. One of these stone inscriptions belonged to Ramazan $950 \mathrm{AH}$ (921 SH). Most of pistachio gardens have been destroyed in recent decades because of water shortage and negligence. One of the old sites left in the western part of the city and near Abbasi Caravansary covers the trees remaining from pistachio garden that are located in a depth of 4-5 meters of the ground. This implantation method, which is described in the following, was used for optimal utilization of water sources and climatic conditions of the region.

There was an old aqueduct in Abbasi Caravansary of Gaz town. Figure 3 indicates aerial image of the old area under study, and Figure 4 shows its status currently. This aqueduct has been abandoned for years. The gardens discussed in this study are located in vicinity of the aqueduct, which are currently not in use and have become a site for garbage accumulation (Fig. 5).

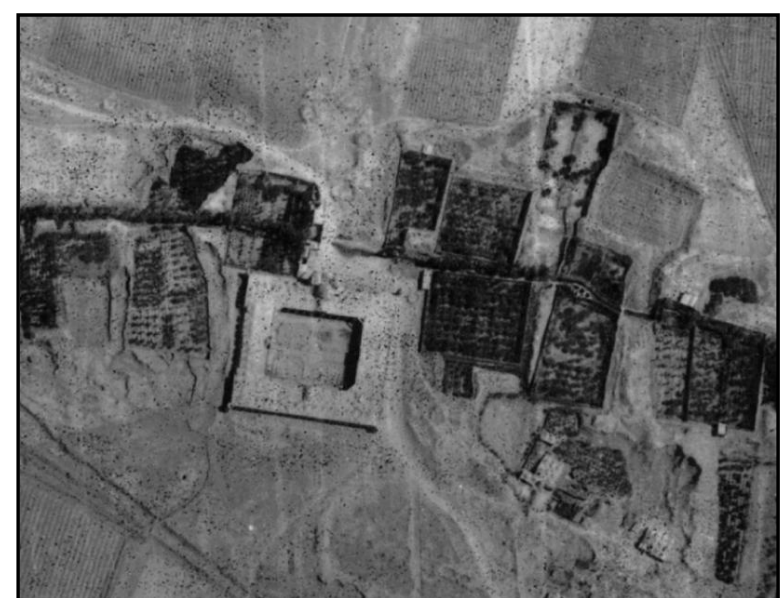

Figure3. Situation of Gaz caravansary and surrounding pistachio gardens (about 50 years ago)

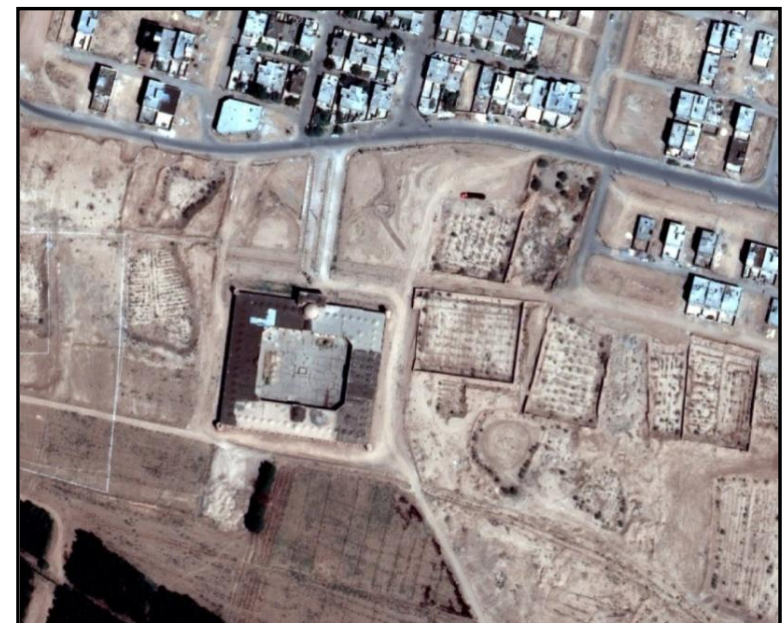

Figure4. Current status of Gaz caravansary and surrounding pistachio gardens

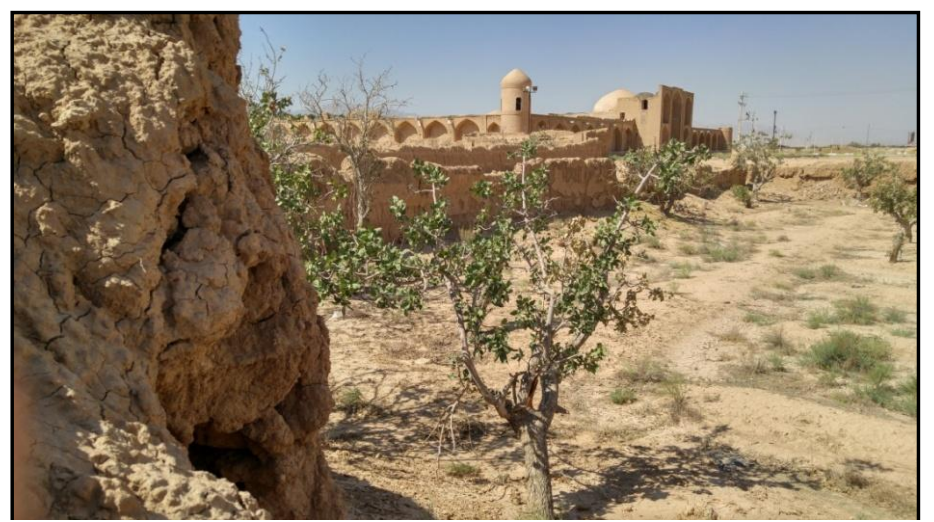

Figure5. Pistachio garden in three-meter depth and Gaz caravansary in its background 
Surface soil of Gaz region is soft lacking adequate strength for locating on the aqueduct canal. Since the plain is relatively flat and the canal slope is low, thus the upper parts of the aqueduct canals were 3-4 meter wide open. Thus, those who had water share and were mainly rich people built their gardens in the vicinity of the aqueduct canal in the ground depth so that they could use the water utilizing the gravity.

\section{REVIEW OF LITERATURE}

Reviving historical and cultural heritage can be one of the good opportunities for economic, social, and cultural prosperity of local communities. Rescuing local cultural values, developing national creativity and ancient customs, along with raising cultural level of the local population, are among the benefits of restoring the historical heritage of a region (Ismagilova et al., 2014). Social, emotional, and symbolic aspects of visiting a touristic region in relation with living quality of residents are important in satisfaction of tourists (Kastenholz, 2012).

Important role of stakeholders in sustainable tourism development is manifested when studying the community-based tourism in less-developed countries (Sotear and Lynnaire, 2014). Sustainable tourism development is facilitated along with integration of sensitivity, knowledge, and environmental behavior as well as local attachment. Environmental knowledge of tourists is increased because of environmental sensitivities, and increasing such sensitivity is directly related to local attachment of the residents Tien-Ming and Homer, 2014). Attachments and interests of local residents are very important factors in determining their support level for sustainable tourism development (Lee, 2013).

One of the outcomes of quick tourism development and negligence to sustainable tourism is sudden pressure on key resources such as water and energy. Results of investigations indicate that local decision makers often lack scientific information and necessary sensitivity required for selection of the best approaches for local tourism development given the new technologies. Involved stakeholders do not possess necessary facilities for appropriate interventions in order to deal with human and environmental changes and unwanted outcomes of development. Hence, raising local understanding in cultural education, historic events and processes, contemporary political and economic issues, and awareness of environmental changes is needed for the region's residents, which are the main stakeholders of the tourism (Wells, et.al, 2014).

Sustainable tourism development is a type of tourism that leads to management of all resources and meets current tourists and the host community without threatening the future generation. Urban spaces have long been the most attractive spaces, because cities are the most civilized human settlements and include major economic, scientific, recreational, and tourism centers, and moreover, they have natural and historical attractions as well. For this reason, they are the main tourism attraction centers. To this end, sustainable tourism as a stable pattern and solution with a long-term perspective in urban planning can direct the communities toward the sustainable development. It can act effectively for preserving and maintaining non-renewable resources including water, soil, and other divine blessings for future generations by meeting economic, sociocultural, recreational, etc. needs for the today generation (Hoseinzade and Lotfitalab, 2014).

Historic town of Gaz Borkhar has various historical and cultural areas that provide great potential for sustainable tourism development. Existence of aqueducts in Gaz has turned it into the agricultural pole of the region and caused economic and social prosperity. According to the historical documents, the number of aqueducts in Borkhar region was 70 from northwest to southeast, and the main source of some them is out of the region. Some of these aqueducts were dried gradually by reduction of rainfalls in the region and thus falling groundwater level. So that their number decreased to 50 in 1972 , and according to the most recent figures, currently there are 14 aqueducts, seven of which are in Gaz. Because of negligence of the users, which its main reason is excessive retailing, all aqueducts collapsed and got dried (Salimi, 2003).

Now all aqueducts in Gaz are dry and abandoned and their water is now just a memory in the minds of old people. Distance of aqueducts was about 20 meters and Gaz aqueducts were almost in parallel. The ground slope in the region decreases from north to south and from west to east. Therefore, most of the aqueducts had a western-eastern direction and flooded the water from the eastern piers of the Zagros to the Borkhar plain. From the source of the aqueduct to the plain belonging to that aqueduct, there was a deep open-wide stream called "Berry", if Berry passed from the field that was beyond the 
same aqueduct, there would be strides. Nevertheless, if Berry passed from the field that did not belong to the water of this aqueduct, it was 3 to 4 meters deep, and without any harvesting, it was completely dominant in the field and the water was landing over the gardens (Salimi, 2003).

Ahmad Aghaee pistachio is the kind of pistachio planted in Gaz Borkhar, which is one of the lateripen kinds. Large size of the almond-shaped fruit and light bone color of the shell caused extension of this type. According to some narrations, Ahmad Aghaee pistachio type was brought to Gaz Borphar in Zandiyeh Era by Haj Ahmad Agha, son of Salim Khan, and therefore, nowadays this type of pistachio is known for his name. Pistachio trees in Isfahan were planted only in Jarghuye and Gaz Borphar regions. Planting pistachio in Borkhar district and Gaz town has a history of five hundred years. The pistachio tree gives fruit since the fifth year. This tree can live as long as 400 years. Regarding pistachio tree in Gaz Borkhar, it has been written than this tree has been source of wealth for its owners (Salimi, 2003).

According to studies, similar to the technique of planting in depth of ground in Gaz has been observed in Africa and in Aran Bidgol town of Isfahan province. Zai or Tassa is a traditional African agricultural method for better use of water and nutrition. The Zai holes have been rebuilt since 1980 by farmers in Burkina Faso based on the current situation in the region. These holes, especially in very light soils, lead to higher productivity of trees and crops by collecting water and nutrients (Itabari \& Wamuongo, 2003).

The Zai system consists of a set of small rounded holes, with a diameter of about $30 \mathrm{~cm}$ and a depth of $20 \mathrm{~cm}$, which are excavated to allow the soil to break through, and water is stored, and it will lead to soil fertility. Organic fertilizer and compost, for fertility improvement, with 4 to 8 grain crops are put in the pit. In the regions with higher rainfall, dimensions of the pits are larger, and thus, more crops are planted in them. This method outperforms twice as the farms that are plowed in a common way (Mati, 2005).

The system similar to Zai in Iran can be observed in Sonbok pit ( $(7 \mathrm{~km}$ northeast of Aran Bidgol Isfahan province) and in sandy area of Band Rig and in southwest of Maranjab Desert. The ground slope, extending from the hillsides Karkas mountains to the desert, and existence of hard ground layers that prevent water penetration into the depths of the soil, has caused the Sonbok pit to have groundwater reservoirs close to the surface. Since the ancient era up to now, using this characteristic following using the land and provision of optimal conditions, the farmers dig up the cylindrical pits with a diameter of 40 to $50 \mathrm{~cm}$ and depth of 1 to $1.5 \mathrm{~m}$ to achieve freshwater. Distance between the pits is about $1 \mathrm{~m}$. They are used for growing watermelon in dry farming.

Deep gardens of Gaz are symbol of a special era and the way of living and interaction of Gaz town people with the climate, which are not abandoned and are vulnerable to complete exhaustion. Texture burnout and burnout outcomes, which ultimately lead to losing its value for the citizens, can be identified in various ways including reduction or loss of viability and safety as well as physical, social, economic, and facilities disruptions. Preservation, maintenance, and reviving old urban elements causes strengthening collective memories of the town residents, and would lead in their participation in optimization and protection of the city in the future (Khodaee and Kamelifar, 2013).

Current status of pistachio gardens is not suitable for urban tourism purposes, and needs beautiful design and beautification. Landscape design is mainly related to designing the green areas that are popular among the people because of their space beauty and pleasantness and role in air filtration with their vegetation, and such areas have always revived the peace for aggressive human of industry and technology era. Achievement of a basis and pattern for designing green space, especially in metropolitans, is faced with many issues, and familiarization with design of gardens and green spaces in the past would be useful, because it provides the proper suggestions with proper understanding of the past and current status (Khak Zand, 2004).

The old gardens of Gaz can be transformed into salient examples of Iranian gardens with some trivial changes. Productivity and creating beautiful landscapes can be mentioned as the general and sometimes common reasons for establishment of most Iranian historic gardens. However, according to the tastes of each era, sometimes religious, recreational, and mostly political and governmental factors were involved in establishment of gardens. Anyway, it can be stated that historical gardens of Iran are symbols of their own eras (Motadayen, 2010). 


\section{Materials ANd Methods}

In designing the urban spaces, transferring message to citizens should be compatible to the cultural characteristics and identity of each community, so that it can be tangible for the citizens and they can visually communicate. Therefore, compatibility between the form and function, which are complementary, is crucially important. How and where the urban spaces are designed considering the identity of the city and society is an important attitude for the selected items. To this end, the elements in the city and parks can be pointed out, which play effective role in instilling urban identity and promoting value sense of the living place for the citizens. Thus, they should be designed in such a way that are comprehensible by the people and match with the city events. Urban elements should address urban landscape and urban identity, because the man-made spaces and environments are mirror-like symbols that reflect the urban identity.

International regulations can be used for highlighting urban and cultural identity of the citizens. One of the international regulations and instructions on preservation and maintenance of historical and cultural heritage is Nara Document. Nara Document was prepared for authenticity and giving identity to the local and national values and heritage, and it has developed charter. The focus of this document is mainly on protective actions and manifestation of human collective memories in cultural and historical heritage. Understanding and giving value to special types of buildings and areas, promoting public awareness and sensitivity to their values, connecting different generations to each other through the shared awareness of the society's individuals about the historical past, and feeling attachment to it in order to enhance the feeling of a share origin in the society's individuals are the basic goals of this document.

In this document, the aim of local and subjective intervention is preserving and promoting historical wealth qualitatively and quantitatively along with modernization and development of the city, improving the function, and preserving the traditions. In such action, a new urban space is constructed, which both preserves basic similarities to the old urban space, and exposes some differences with it in terms of nature and meaning.

In addition, the concept of collective memory that is referred in this document is regarded as the memories shared by the residents of a place from their shared past. With connecting the society members, these memories create social coherence and promote collective spirit and participation of society individuals, which play significant role in reviving the urban textures.

Considering the mentioned material and given the fact that one of the goals of urban renovation in Iran is preserving the identity of the city, paying attention to the actions in the city (in the old past) is a suitable guideline for preservation and development of urban space. It is a clear fact that layers of historical and natural events that have shaped the city over its life cause creation of a connected and coherent structure in the city. Given the Nara Document and current status in Gaz region, the best action is reviving the gardens, which are rooted in collective memories of the city residents in the way of climatic utilization and compatibility.

These gardens need organization and appropriation. Urban environmental appropriation means providing motor, auditory, visual, social, etc. comfort conditions for the people living in the city. Creation of appropriate urban spaces paves ground for improvement of social interactions and reduction of individual and collective depression and anomalies and directs the human being toward the community and the collective use of spaces in such an era when the occupation and residence are shaped based on a person-centered approach.

Burnout condition and weak economic life in the gardens and even in its adjacent caravansary is such that justifies maximum intervention without paying attention to preservation of the identity and existing values. However, renovation experiences show that the negligence to existing qualities of the city can lead to the failure of the main goals. Interpretation of the historic relevance of urban green spaces with valuable buildings and developing methods for protecting both of them, with regard to social mental values, are one of the main concerns of this paper.

Although old erosive sites are per se as the urban problems, they are actually potentials that can become a good opportunity by proper identification, optimization, planning, refurbishing and refining. Considering sustainable urban development, significance of urban renovation and optimization in these textures have become more than ever. 
Sustainable development includes offering solutions against traditional structural, social, and economic development patterns, so that such issues as destruction of natural resources, ecosystem destruction, injustice, pollution, excessive population increase, and low human living quality are avoided. Sustainable development is origin of peace and stability (since it is derived from the nature's thoughts), and it is regarded as the systematic reaction toward all human problems, which result from the industry era. Green space has important and undeniable role in developing sustainability in the cities and sustainable urban development.

Since the concept of landscape and open space as major elements in the city has been recently more considered, Iranian garden has long been famous in the culture of this land, and now it has global fame, these gardens can be revived as a symbol of Iranian garden. Iranian garden or "Bagh Sara" refers to its unique structure and design. Iranian garden is connected to the history of aqueduct emergence and the primary Iranian gardens were constructed on the outlet path of aqueducts. Examples of these gardens can be observed in Isfahan, Kerman, Tabas, Yazd, Gonabad, and Birjand, and most desert areas of Iran.

In Islamic Era, water gained functional role in architecture. That is, the water is so involved in the construction and building that practically it cannot be considered as separate from the constructed form. Water is one of the main elements in Iranian garden, part of which is used for irritation of plants and part of which is utilized for creating beauty in the design. Gardens not only manifest their construction's climate and historical eras, but also manifest the human thoughts and beliefs, and structures of the gardens have considerably changed by changing thoughts, ideals, and beliefs. Iranian historical gardens are perfectly symbolic and describe idealistic relationship between human and nature. Gardens in Iran have a significant role in instilling the sense of place to the visitors due to their laconic and sacred qualities, in addition to the semantic and historical burden.

Iranian garden has three unique structures and designs. First, it is on the waterway. Second, it is enclosed with high walls, and third, there are mansion and water pool inside the garden. These three characteristics distinguish Iranian gardens. These three parameters are available in the gardens under study. Iranian gardens, as perfect structures, represent close relationship between the cultural and natural grounds, and are signs of compatibility of human needs and the nature.

The nature has always a response and solution for everything, and it is a perfect and adequate pattern for all creatures that are created in it. In the current era, known as technology and industry era, human beings, through sheltering the technology, have created a boundary between themselves and nature, which are themselves born in it and are part of it. They are completely away from the nature and even unconsciously destroyed it. The current pollution is due to lack of knowledge of the designers and waste of resources in the wrong designs that have created an unhealthy system. Accompaniment with the climate and nature of the living place guarantees survival and sustainability of the residents. Thus, this coordination and consistency should be taken into account for achievement of sustainable development.

One of the Iranian manifestations in consistency of human needs and nature is digging up aqueduct in arid and semi-arid regions of the country. "Kariz", "Kahriz", or aqueduct is called as the tunnelshaped duct dug up underground for flowing the water. This duct, which is at the depth of the ground for connecting stream of wells with the same source well (the largest aqueduct well), is used for directing the water and water management for agriculture and other usages. The aqueduct canal may have length of thousands meters to reach the ground surface. Finally, water of these aqueducts reach the ground surface, and this point is called aqueduct opening, head, or wellspring.

Aqueduct construction technology was developed early at the first millennium BC in arid mountainous region of Iran, and allowed the farmers in these regions to have plantation and farming in the long periods of drought when no surface water could be accessed. These aqueducts gradually became common in other regions of the world, and currently there are many aqueducts from China to Morocco an even in America continent. Therefore, aqueducts are one of the beautiful manifestations of accompaniment of Iranians with their climate, which can surprise domestic and foreign tourists. Aqueduct has several benefits as a water harvesting method. First, the main part of the water channel is located underground, resulting in reduction of water loss due to evaporation and penetration into the soil. Secondly, the system's power is supplied through the gravity and there is no need for a pump; 
and thirdly, underground water is used as a renewable source, which in turn brings about other advantages; advantages that guarantee sustainable development in the region.

Pistachio tree, which is subject of current study, is one of the most compatible trees for the climate of Iran. After handmade carpet, this product in Iran is the second largest non-oil export good. Calling it as the Green Gold traditionally denotes importance of pistachio in Iran. This tree represents fall in autumn, and sleeps in winter. Root generation is axially and vertically and penetrates through the soil up to over 2 meters. The pistachio tree is a sunshine loving plant and survives at temperatures between -20 and $+45{ }^{\circ} \mathrm{C}$. It needs less than $35 \%$ moisture and needs moderate water. The proper pruning for it is the open center and parabolic pruning (Fig. 6).

Pistachio tree is highly resistant against drought and dryness, so that the old trees can be survived without irritation for a long period (even for several decades). The abandoned pistachio gardens, which are subject of this work, are situated at the east of the famous caravansary of Gaz, and are evidence for this claim.

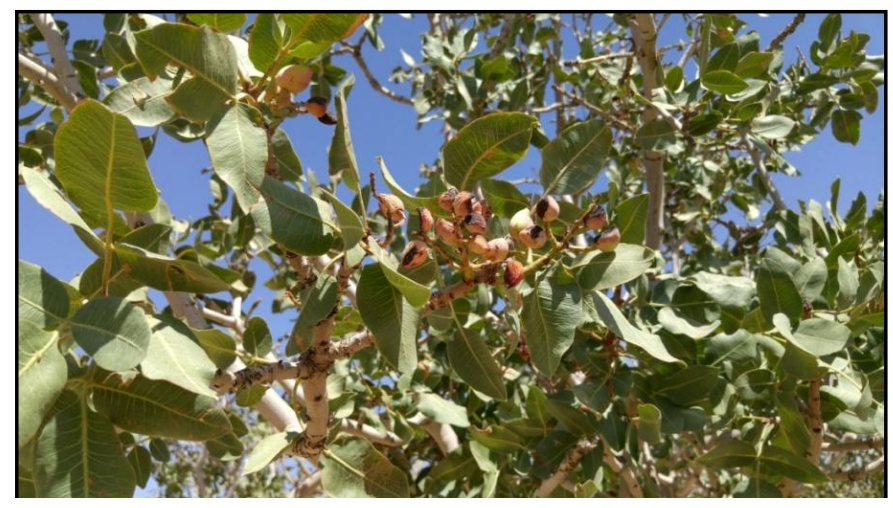

Figure6. Pistachio tree in Gaz town's garden

\section{CONCLuSion}

According to the studies, role of the local residents as the utilizers and the main owners of historical regions in proper use of the place and sustainable tourism development in developing countries such as Iran have been proved. Therefore, interest and awareness of local residents regarding cultural issues, historical events, and environmental changes of their place of living have more important role than the organizations responsible for tourism development in the region, and leads to higher satisfaction level in the tourists and visitors.

Selection of urban elements that play effective role in instilling urban identity and promoting valuable sense in citizens attracts attention of them for supporting sustainable development. Situation of gardens, aqueducts, and caravansary in Gaz is such that it is eligible for the people of city and tourists, and it is in perfect compatibility with the urban events of Gaz. Thus, historical relevance between green spaces and valuable buildings is reminded in the minds and they perceive necessity for protection of both of them.

The pistachio gardens adjacent to Gaz Borkhar's caravansary, which have been deeply dug and planted in order to coordinate with the nearby aqueducts, are among the attractive and beautiful manifestations of the residents' attention and their intelligence in harmony with the nature of the region. Pistachio gardens have currently been abandoned, while they can be modernized by a little facade and landscape design, and can be used as cultural - educational resort.

Since paying attention to the local identity is one of the most important and effective design parameters in reconstruction and renovation of any historical site, thus, the old usage of the region as well as its climatic intelligence should be preserved in order to transfer to the next generations.

Since these trees and gardens were living not so long ago, their preservation, maintenance, and reviving strengthens collective memories of the residents, and will result in public participation for optimization and protection of the gardens in the future. Therefore, continuation of collective memories of the citizens and transferring to the tourists regarding presence of the aqueducts and deep gardens will be realized. 
Deepening the gardens, planting the pistachio trees, and current status of the gardens imply climatic appropriateness and sustainability of this technique. Sustainable development and preservation of the urban environment will be realized by reutilization of these gardens. Thus, Gaz region with its touristic attractions, in addition to existing green spaces, would enjoy a permanent resort compatible with the climates, which meet goals of the city's sustainable tourism development.

As above mentioned, given type of its architecture, situation, and other available potentials, Gaz caravansary can be turned into an attractive historical touristic site with natural beauties. Due to its proximity to the city of Isfahan, Gaz is of great potential to become one of the most important tourist destinations in Isfahan province. The arrival of international tourists in this city can have tremendous effects on the economic prosperity of the city and the creation of new job opportunities.

With reviving the pistachio gardens adjacent to the caravansary, which were constructed by the intelligence of their owners and still surviving, again a representation of Iranian garden with the three main symbols of water (aqueduct), garden, and historical building, will be revitalized in this region. Because of reviving the urban gardens given the green space usage and creation of recreational space, commercial productivity of pistachio trees in these gardens is not intended. Although pistachio, like other fruit trees, needs water and if it takes less than natural level of water during the growth season, the tree will react and its productivity and even life is reduced, the tree still can survive. Hence, pistachio is one of most fruit-bearing and useful trees that can adapt to low water condition. Since the product quality is not of importance here, with a little care it is possible to have fruity and green tress. In addition to beauty of pistachio trees (considering the shape of leaves and fruit), the visitors will become familiar with the pistachio tree and fruit that is one of the major non-oil export goods and somehow the second symbol of Iran in the world. Pistachio is a beautiful tree and symbol of Iran. With placing it in the reconstructed site and modernizing the farming gardens, the people can be familiarized with it.

Supplying the water needs and preventing from damage to trees and plants by pests and diseases are the main concerns in green space preservation and maintenance. However, the pistachio trees in this region have been abandoned for a long time, and they are yet sound without meeting these needs. This fact can be considered as a positive point in developing and preserving green space and tourism in the region.

Due to the presence of scattered and old pistachio trees in the city of Gaz, large and old pistachio trees can be displaced to this place with the proper arrangements to create a suitable landscape in these gardens. On the other hand, the shape of the crown in pistachio trees and their pruning potential will make it possible to create a natural and extensive shadow for the use of tourists. Due to the old age of existing trees and the widespread root system in them, appropriate crown and a good height can be achieved with a little care. The other point which will be evident in these gardens is lack of wind in the garden (in addition to wind at ground surface) and stop of surrounding noises and reduction of noise pollution caused by the traffic of light and heavy vehicles on the street and the surrounding highways. Which peace and comfort in such space.

These revived gardens, in addition to beauty and resort use, can be utilized as educational garden especially for the children as the next generation. Existence of aqueducts will be the other attraction in this site, which can help to increase awareness of people about the old ways of utilization of available resources and the attempts for sustainable access to water resources. Familiarization with aqueduct through schematic reconstruction of aqueduct for visit purpose, familiarization with the pistachio tree, familiarization with creativities of people of this land for coordination with the climate and climatic limitations, training optimal use of available resources and compatibility with the climate and nontendency to unsustainable development may be goals and capabilities of this educational garden.

It worth noting that this planting method can be used also in similar contexts such as soil and sand excavation mines by in-situ studies.

\section{REFERENCES}

[1] Kruse, E., Eslamian, S., 2017, Groundwater Management in Drought Conditions, Ch. 11 in Handbook of Drought and Water Scarcity, Vol. 3: Management of Drought and Water Scarcity, Ed. by Eslamian S. and Eslamian F., Francis and Taylor, CRC Press, USA, 275-282. 
[2] Araghinejad, S., Hosseini-Moghari, S.-M., Eslamian, S., 2017, Reservoir Operation during Drought, Ch. 12 in Handbook of Drought and Water Scarcity, Vol. 3: Management of Drought and Water Scarcity, Ed. by Eslamian S. and Eslamian F., Francis and Taylor, CRC Press, USA, 283-292.

[3] Eslamian, S., Khosravi, B., Sayahi, M., Haeri-Hamedani, M. 2017, Crises Management Planning and Drought Management Plans, Ch. 13 in Handbook of Drought and Water Scarcity, Vol. 3: Management of Drought and Water Scarcity, Ed. by Eslamian S. and Eslamian F., Francis and Taylor, CRC Press, USA, 293-304.

[4] Halbac-Cotoara-Zamfir, R., Eslamian, S., 2017, Functional Analysis of Regional Drought Management, Ch. 14 in Handbook of Drought and Water Scarcity, Vol. 3: Management of Drought and Water Scarcity, Ed. by Eslamian S. and Eslamian F., Francis and Taylor, CRC Press, USA, 305-328.

[5] Zahraei, A., Saadati, S., Eslamian, S., 2017, Irrigation Deficit: Farmlands, Ch. 16 in Handbook of Drought and Water Scarcity, Vol. 3: Management of Drought and Water Scarcity, Ed. by Eslamian S. and Eslamian F., Francis and Taylor, CRC Press, USA, 343-358.

[6] Amiri, M. J., Eslamian, S., Bahrami, M., Yousefi, N. 2017, Deficit Irrigation: Greenhouse, Ch. 17 in Handbook of Drought and Water Scarcity, Vol. 3: Management of Drought and Water Scarcity, Ed. by Eslamian S. and Eslamian F., Francis and Taylor, CRC Press, USA, 359-372.

[7] Ostad-Ali-Askari, K., Shayanejad, M., Eslamian, S., Zamani, F., Shojaei, N., Navabpour, B., Majidifard, Z., Sadri, A., Ghasemi-Siani, Z., Nourozi, H., Vafaei, O., Homayouni. S.-M.-A., 2017, Deficit Irrigation: Optimization Models, Ch. 18 in Handbook of Drought and Water Scarcity, Vol. 3: Management of Drought and Water Scarcity, Ed. by Eslamian S. and Eslamian F., Francis and Taylor, CRC Press, USA, 373-390.

[8] Eludoyin, A. O., Eludoyin, O. M., Eslamian, S., 2017, Drought Mitigation Practices, Ch. 19 in Handbook of Drought and Water Scarcity, Vol. 3: Management of Drought and Water Scarcity, Ed. by Eslamian S. and Eslamian F., Francis and Taylor, CRC Press, USA, 391-402

[9] Irshad, S. M., Eslamian, S., 2017, Politics of Drought Management and Water Control in India, Ch. 22 in Handbook of Drought and Water Scarcity, Vol. 3: Management of Drought and Water Scarcity, Ed. by Eslamian S. and Eslamian F., Francis and Taylor, CRC Press, USA, 447-460.

[10] Pati, R., Eslamian, S., 2017, Drought Management for Horticultural Crops in India, Ch. 23 in Handbook of Drought and Water Scarcity, Vol. 3: Management of Drought and Water Scarcity, Ed. by Eslamian S. and Eslamian F., Francis and Taylor, CRC Press, USA, 461-482.

Citation: Elham Zadbagher-Seghalani et.al., "Climate Intelligence, a Strategy for Sustainable Urban Tourism Development in Historic City of Gaz Borkhar, Isfahan, Iran”, International Journal of Constructive Research in Civil Engineering, 4(3), pp. 1-10. DOI: http://dx. doi.org/10.20431/2454-8693.0403001

Copyright: (C) 2018 Authors. This is an open-access article distributed under the terms of the Creative Commons Attribution License, which permits unrestricted use, distribution, and reproduction in any medium, provided the original author and source are credited. 